\title{
A Model for Effective Online Instructional Design
}

\author{
Li-Ling Chen \\ California State University at East Bay, USA
}

\begin{abstract}
With the ever-increasing popularity of online instruction in education or e-learning in corporate training, there is a strong need for developing an effective instructional design model to facilitate the development and delivery of online learning environments. A poor-designed online course often confuses online students, loses their focus, and makes them feel frustrated. Online students will not know where to start, what to do, when to communicate, and how to learn if an online course is not well-designed. Thus, developing a pedagogically effective instructional design model is essential now more than ever as more and more learning moves to virtual classrooms.
\end{abstract}

\section{Introduction}

In the past decade, online instruction continues to grow rapidly. With the popularity of online instruction in education, there is a strong need for a pedagogically effective instructional design model for online education to facilitate the development and delivery of engaging online learning environments. A poorly designed online course often makes students get lost, loses their interests, and feels distressed. If an online course is not well-designed, students will not know where to start, what to do, when to communicate, and how to learn. The status will become even worse if a student is still learning how to operate the technology aspects of an online course. With unclear instruction, ambiguous organization, and inefficient applications, the focus of online learners will be on technology, not on learning which creates more obstacles for online learners.

Instructional design (ID) also called instructional systematic design (ISD) is "the practice of creating instructional experiences which make the acquisition of knowledge and skill more efficient, effective, and appealing" [10]. An effective ISD model benefits both instructors and learners. An instructional design serves as a framework and also a tool that provides guidance for the structure and organization of a course design. With systematic guidance, it helps to lead learners to focus on a topic quickly and to remove distractions, yet it still allows learners to take control of their learning. It also helps instructors to organize contents, to sequence instruction effectively, to assist and support learners, and to promote engaging, meaningful, and active learning. Therefore, it is essential now more than ever as more and more learning shifts to online.

The purpose of this paper is to address principles of effective online instructional design and then to propose a stand-alone online ID model, particularly relevant for online course development with the consideration of learning theories and pedagogical philosophy. The proposed ISD model in this paper will effectively guide an online instructor and educator to better design a quality online course which promotes and enhances online students' focus on active and engaging learning.

\section{Literature review}

The review of literature will start from reviewing the two most frequently mentioned traditional ISD models, ADDIE (Analysis, Design, Development, Implementation, and Evaluation) and Dick, Carey, and Carey's model. Then, the literature review will examine the current five ISD models or standards that are mostly cited and applied for designing and developing an online or a hybrid class.

\subsection{Traditional ISD models}

Instructional design models have some history in education and thus many instructional design models exist yet few are specific to course design for online teaching and learning. The two most frequently cited traditional ID models are the ADDIE model [6] and Dick, Carey, and Carey's model [3]. The ADDIE model offers five universal course design principles: Analysis, Design, Development, Implementation, and Evaluation (ADDIE).

Like all ID models, both pros and cons have been claimed with ADDIE. Its advantages include: providing structured guidance for design, serving as a valuable checklist to ensure a solid course design, and including a great focus on implementation and evaluation. The disadvantages of ADDIE include that the analysis step is not being broad enough in the design process; the model is too linear and not flexible; and it does not encourage inspiration [9].

Sequentially similar to the ADDIE model, Dick, Carey, and Carey's ISD model is more specific and rigid to each instructional step [3]. Their model focuses on real-world settings, considers learners' 
needs, assesses learners' prior knowledge levels, and integrates learning and performance context into the design. The model is well accepted and respected in higher education and business settings because it is well-researched and it relies heavily on theoretical principles of learning.

Although Dick, Carey, and Carey claim that their ISD model is also applicable to online instructional design, many educators criticize that their model is "rigid, cumbersome, driven by predetermined objectives, thus incompatible with learnerdetermined objectives. The model is also instructorfocused, assumes the learner is a consumer of content and materials, and not active in the learning process" [7].

Apparently, both ADDIE and Dick, Carey, and Carey's models provide a great guidance for designing instruction. At the same time, critics of the models also indicate that they are too linear and inflexible. Their designing process is also driven by predetermined instructional objectives which are contradictory to learner-centered learning with learner-determined objectives.

\subsection{Online instructional design models}

Although distance education has been existing for a long time, the history of online instruction or elearning has just started in early 1990's. Thus, there are few online instructional design models, theories, and standards exist. Literature review reveals that there are five instructional design models, theories, and standards relevant to online instruction or elearning design. They are: (1) Alonso, Lopez, Manrique, and Vines' E-Learning instructional model, (2) the Instructional Design Model for Online Learning (IDOL), (3) Roblyer's online and blended learning design theory, (4) the online instruction rubric by Quality Online Learning and Teaching (QOLT), and (5) Quality Matters (QM) Publisher Rubric. Each of the model or rubric will be described and reviewed below.

In 2005, Alonso, Lopez, Manrique, and Vines proposed a web-based e-learning education model with a blended learning approach [1]. They describe their model is "a psychopedagogical instructional model based on content structure, the latest research into information processing psychology and social contructivism, and define a blended approach to the learning process" (p. 217). They claimed that the purpose of their model is "for learners to be engaged by the e-learning contents to the extent that they get to understand things that they did not comprehend before. This will make them ready to practice and take action to perform new activities." (p. 222).

In their model, there are seven main steps: Analysis, Design, Development, Implementation, Execution, Evaluation, and Review (See Figure 1.). Apparently, their model was built upon ADDIE model with the addition of two phases, Execution and Review.

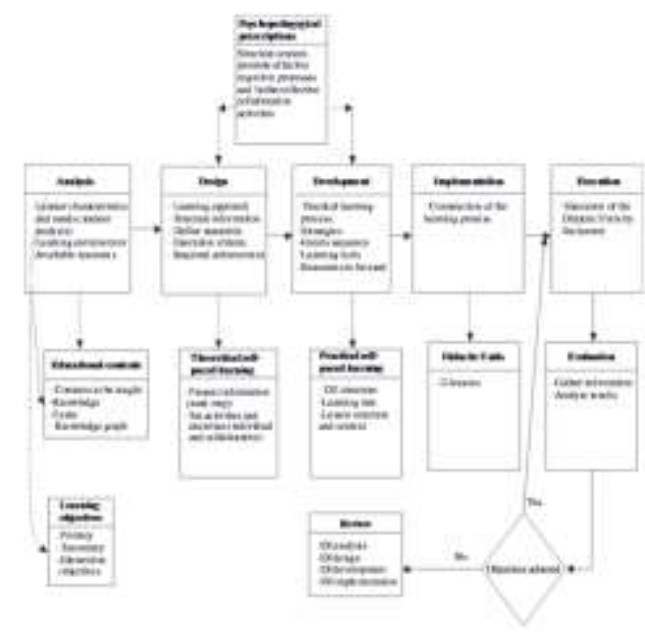

Figure 1. Alonso, Lopez, Manrique, and Vines' elearning instructional model with a blended learning approach

This IDOL model, designed and proposed by Siragusa, Dixon, and Dixon [12], gears toward online course design in higher education with three proposed main steps: analysis, strategy, and evaluation. One can tell that the model derives from the two above-mentioned traditional instructional design models, ADDIE and Dick, Carey and Carey's model. It presents 24 pedagogical considerations when designing an online learning. The main drawback of the model for online design is that it is only recommended for use alongside with other ID models and is inefficient to use alone for designing an online course.

Roblyer's instructional design model was proposed in his book, entitled "Introduction to Systematic Instructional Design for Traditional, Online, and Blended Environments" published in 2015 [10]. His theory also draws from ADDIE and Dick, Carey, and Carey's model. Besides the traditional instructional design process, he proposes how to organize traditional, online, and blended learning environments. Strictly speaking, it is not an online instructional design model but just suggestions and considerations for online instructional design.

The rubric for online instruction by QOLT was first released in 2010 [11]. It is a state-wide program developed by the California State University System. It provides a framework for online course design and delivery and it also serves as a means for supporting in developing online instruction. According to QOLT [11], the rubric can be used for designing online learning in two ways: " 1 . as a course "selfevaluation" tool - advising instructors how to revise an existing course to the Rubric for Online 
Instruction. 2. As a way to design a new course for the online environment, following the rubric as a road map." Although the rubric provides a great checklist to design online courses, it overlooks the actual implementation and evaluation of an online instruction.

Quality Matters Publisher Rubric [8] was created by Quality Matters (QM), a non-profit organization dedicated to assure the quality of online and blended instruction. There are two sets of rubric: one for higher education and the other one for K-12 education. The rubric was created to address the need of design standards for higher education and K-12 educational settings to guide the design of online and blended instruction. The QM rubric is also a great guide for designing online courses. Like QOLT rubric, the actual delivery, implementation, and assessment of an online instruction are not addressed.

\section{A pedagogically effective model for online instructional design}

Based on the literature review, we can find that there are some basic principles for designing and developing an effective online course. The basic principles can be theorized and diagramed as an online course design model (See Figure 2.). There are five main principles or steps in the model: Identify, Choose, Create, Engage, and Evaluate (ICCEE). The unique characteristic in the model is that all main steps and their associated sub-steps majorly follow a sequential order, yet they can be in circular order as well. By following the model, an online instructor can maximize the efficiency of designing an online course.

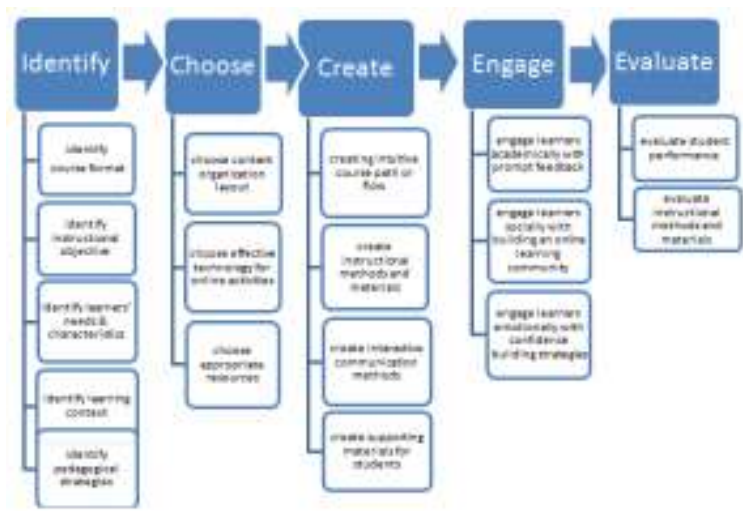

Figure 2. Online instructional design model

Step 1: Identify. Because the nature of an online course is very different from a traditional face to face course and a hybrid course, identifying a course format becomes essential in the initial process when designing an online course. Course formats range from totally face-to-face class to blended courses with small portion of online components, to high portion of online components, or to an entirely online class. An online instructor needs to identify which course format that he/she would like to adopt for instruction first. The course format identification will help the instructor to better identify instructional objectives.

After a course format is set, an instructor can move the step to identify instructional objectives. When identifying instructional objectives for online courses, online instructors should consider questions, such as what are the terminal objectives for the online or blended course? Are the terminal objectives mandated by the institution that the online course will be offered? Is there any flexibility that the instructor can create his/her terminal objectives for the learners?

When terminal objectives or course objectives are set, instructors should identify their learners' needs and characteristics. With the understanding of the needs and characteristics of the learners, online instructors can better identify technologies to maximize their students' learning. For example, instructors can better choose a technology tool to incorporate into their online course design if they know their student's prior experience of technology use. Another example is an online instructor can chose a delivery system that complies with Section 508 if there are students with disabilities in his/her online class.

Then, online instructors have to identify and analyze the learning context. Different from traditional teaching which classrooms or computer labs are the main learning contexts, online learning context for online instruction focuses on web-based online learning environments. It is very essential for online instructors to provide a comfortable, safe, and collegial online learning environment for their online learners.

After appropriate technologies have been identified to use for delivering an online course, an online instructor can now move to identify appropriate pedagogical strategies. In this stage, online instructors can ask themselves what learning and teaching approaches that he/she would like to apply, behaviorism, cognitivism, constructivism, project-based learning, or student-centered learning?

Step 2: Choose. After identifying appropriate necessary formats and elements for an online instruction, then an online instructor can begin to choose. At this stage, online instructors choose content organization layout which is a way to organize their online course contents and materials, linear or nonlinear. Choosing content organization format is essential in this step as it influences students' first impression of the online courses as well as their access to and navigation of the course contents. Poorly organized online course contents 
will confuse its learners, and make them lose patience to navigate around.

After content organization layout has been chosen, online instructors need to choose effective technology tools to facilitate various online activities. For example, online discussion is one of the major activities for online learning, online instructors need to choose effective technology tools to facilitate online interaction and communication. A user friendly online discussion tool will ease students' anxiety as well as promote a more dynamic online discussion. For content presentation, online instructors can choose technology that is familiar to students or easy to use to present information to students.

In this planning stage, online instructors will have to choose appropriate resources to help their learners learn or enhance their learning. The resources can include both curriculum related resources, technical support resources, and university-based mentoring supporting resources.

Step 3: Create. The third step is to create or to develop. At this step, online instructors start building and creating intuitive course path or flow, create instructional methods and materials for content presentation, assignment, and assessment, create interactive communication methods, and create supporting materials for students.

To build and create intuitive course path or flow, online instructors can work with their institutionally designated instructional designer to sketch or story board about the course site architecture in a learning management system. At this stage, online instructors have to decide whether they would like to display their course contents in a linear or hierarchical way. They also have to decide how to cluster their course contents in order to enhance their students' learning.

After course site architecture has been decided, online instructors can move to create and develop materials for instructional content presentation, assignments, and assessment. Creating and developing instructional materials require a logical plan and organization. For course contents involving multimedia, online instructors can work collaboratively with professional staff in faculty support offices to make sure audio, video, and graphics all work smoothly and comply with accessibility regulation. Assignment submission and assessment feedback also need to create logically and transparently so that online students can track their progress for improvement.

When instructional materials, assignments, and assessment methods have all been in place, online instructors have to focus on how to create and facilitate interactive communication methods. The establishment of an interactive communication or building a robust online learning community is one of the major keys in determining the success of an online instruction. In this stage, applying a social media technology usually will help in facilitating dynamic communication.

Step 4: Engage. According to a research report, online learning tends to have a high drop-out rate [2], [4], how to retain and engage online learners becomes essential. According to Willging and Johnson [13], the factors which cause online students to drop out from online courses include isolation, disconnectedness, and technological problems. Therefore, in the implementation stage for an online course, online instructors should focus on the process of how to carry out the online learning. Casimiro [2] proposed five conditions that could have supported the engagement of online student: nature of discussion questions, the mitigating factors for the level of student response, learning community, student characteristics, and teacher facilitation. He furthermore claims that "of these five, the nature of discussion questions, quality of student response, and learning community appeared to be the best to promote cognitive engagement" (P. 441). According to the author's conclusion, online instructors can engage students from three perspectives: academic, social, and emotion. To engage learners academically in an online class, online instructors could provide prompt feedback for students' performance in their assignments and projects as well as their questions regarding technological issues. Providing immediate feedback for students' questions will ease out student's worry and keep students stay in their online class. Offering prompt and just-in-time feedback for students' assignments and projects allows learners to track their progress and keep on task.

Student's feeling of isolation in an online class is another influential drop-out factor and it can also be detrimental for student's learning. Building a positive online learning community is the key to solve the problem. Online instructors can apply various technology tools to facilitate and promote the establishment of online learning environment. The tools include: traditional text-based discussion boards, forums, multimedia-based discussion boards, such as VoiceThread, wiki, or course texting functions, such as Remind, to establish an online learning community. To make sure the learning community is comfortable, safe, and positive, online instructors should set online netiquette guidelines for their learners before the class starts. While implementing or delivering an online class, online instructors should facilitate and monitor their online discourse in all discussion platforms constantly.

To engage online learners emotionally, online instructors can apply some instructional strategies to increase student's confidence level. When students feel confidence in an online class, they will have a better chance to succeed. Strategies to increase student's confidence in an online class include: providing extra credit, offering visual or musical aid, 
and so on. "A picture is more than 1000 words." Providing visual or musical aid can help students, especially for the second language learners, to comprehend the new materials easier. This includes assessments that require online learners to demonstrate mastery.

Step 5: Evaluate. The final step in this model is evaluation. Student assessment should be holistic and formative. Online instructors can evaluate students' performance with multiple strategies, such as projects, presentation, assignments, test, communication posts, etc. Students' performance in an online class should also be evaluated progressively and periodically. Online instructors should also evaluate the effectiveness of their instructional methods and materials by checking with their online students either via survey, questionnaire, interview, online observations, or others.

\section{Discussion}

There are several advantages of applying the five principles proposed in this model for online course design. First, the model is built upon with considerations from traditional ID models as well as currently existing online ID models. Furthermore, both pedagogical approaches and learning theories are also taken into account.

Second, it is well-designed by outlining conceptual framework for online instruction. The researcher has received state wide recognitions and awards for her outstanding online course design and teaching and also has accessed to numerous exemplary online courses. To develop the model, she and her research team had listed essential elements of the theoretical framework for online instruction based on the examination of various online courses. They reviewed online courses, made tables and charts to compare ID theories and elements that were used for the online course design.

Third, the model is flexible. Online instructors can tailor the instructional sub-steps in the model to meet their own specific online teaching needs. In addition, online instructors can go back to previous steps to revise their course design and contents if they deem a need.

Fourth, the model is learner-centered. According to the model, online instructors have to identify their learner's needs, prior knowledge, characteristics, and learning context in order to provide appropriate instruction that matches their students' learning needs. The model considers the importance of engaging learners from academically, socially, and emotionally which has not been taken into account in any of the existing five ISD models related to online instruction.

The proposed ICCEE (Identify, Choose, Create, Engage, and Evaluate) model is still in its infancy. Although the researcher has adopted, tested out, and proved the effectiveness of the model in her online instruction, it is suggested that more empirical researches can be done.

\section{Conclusion}

The proposed ICCEE model can provide online educators or instructors an effective guidance and checklist when designing online course materials. A proper implementation of the model can support online student's engagement, involvement, motivation, and focus on learning. The five basic principles are in a both linear and circular process. That is, online instructors can return back to any previous step to modify their instructional design while they develop or deliver online instruction. The end goal of the online instructional design model is to assist online instructors to better design online courses or lessons, to facilitate online students focusing on their learning, and to promote active teaching and learning.

\section{References}

[1] Alonso, F., Lopez, G., Manrique, D., \& Vines, J. M., (2005). An instructional model for web-based e-learning education with a blended learning process approach, British Journal of Educational Technology, 36(2), 217 235. http://www.fisme.science.uu.nl/publicaties/ literatuur/2005_modelforwebbasedelearning.pd (April 28, 2016)

[2] Casimiro, L. T., (2016). Cognitive engagement in online intercultural interactions: Beyond analytics, International Journal of Information and Education Technology, 6(6), 441-447.

[3] Dick, W., Carey, L., \& Carey, J. O., (2014). The systematic design of instruction. 8th Ed. New Jersey: Pearson Education, Inc.

[4] Haynie, D., Experts debate graduation rates for online students. US News: Education, http://www.usnews.com /education/online-education/articles/2015/01/30/experts -debate-graduation-rates-for-online-students (Jan. 30, 2015).

[5] Merrill, M. D., Drake, L., Lacy, M. J., \& Pratt, J., (1996). Reclaiming instructional design. Educational Technology, 36(5), 5-7.

[6] Molenda, M., (2003). In search of the elusive ADDIE model. Performance Improvement, 42(5), 34-37.

[7] Morrison, D., (2013). "Start here": Instructional design models for online courses. Online Learning Insights. https://onlinelearninginsights.wordpress.com/tag/onlinepedagogy-2/page/5/_(April 25, 2016)

[8] Quality Matters (2015). QM publisher rubric: https://www.qualitymatters.org/_(May 1, 2016) 
[9] Quinn, C., (2010). The great ADDIE debate. http://blog.learnlets.com/?p=1489. (Access date: May 5, 2016).

[10] Roblyer, M. D., (2015). Introduction to systematic instructional design for traditional, online, and blended environments. New Jersey: Pearson Education, Inc.

[11] Rubric for Online Instruction (2010). QOLT (Quality Online Teaching and Learning). http://courseredesign. csuprojects.org/wp/qolt/(Access date: May 5, 2016)

[12] Siragusa, L., Dixon, K. C., \& Dixon, R., (2007). Designing quality e-learning environments in higher education. http://www.ascilite.org.au/conferences/ singapore07/procs/siragusa.pdf_(Access date: May 1, 2016)

[13] Willging, P. A. \& Johnson, S. A., (2004). Factors that influence students' decision to drop out of online courses. Journal of Asynchronous Learning Networks, 8(4), 105118. 